\title{
Surface adsorption in strontium chloride ammines
}

\author{
Ammitzbøll, Andreas L.; Lysgaard, Steen; Klukowska, Agata; Vegge, Tejs; Quaade, Ulrich J.
}

Published in:

Journal of Chemical Physics

Link to article, DOI:

$10.1063 / 1.4800754$

Publication date:

2013

Document Version

Publisher's PDF, also known as Version of record

Link back to DTU Orbit

Citation (APA):

Ammitzbøll, A. L., Lysgaard, S., Klukowska, A., Vegge, T., \& Quaade, U. J. (2013). Surface adsorption in strontium chloride ammines. Journal of Chemical Physics, 138(16), 164701. https://doi.org/10.1063/1.4800754

\section{General rights}

Copyright and moral rights for the publications made accessible in the public portal are retained by the authors and/or other copyright owners and it is a condition of accessing publications that users recognise and abide by the legal requirements associated with these rights.

- Users may download and print one copy of any publication from the public portal for the purpose of private study or research.

- You may not further distribute the material or use it for any profit-making activity or commercial gain

- You may freely distribute the URL identifying the publication in the public portal

If you believe that this document breaches copyright please contact us providing details, and we will remove access to the work immediately and investigate your claim. 


\section{AIP $\begin{gathered}\text { molowanat } \\ \text { Chemical Physics }\end{gathered}$}

\section{Surface adsorption in strontium chloride ammines}

Andreas L. Ammitzbøll, Steen Lysgaard, Agata Klukowska, Tejs Vegge, and Ulrich J. Quaade

Citation: J. Chem. Phys. 138, 164701 (2013); doi: 10.1063/1.4800754

View online: http://dx.doi.org/10.1063/1.4800754

View Table of Contents: http://jcp.aip.org/resource/1/JCPSA6/v138/i16

Published by the American Institute of Physics.

\section{Additional information on J. Chem. Phys.}

Journal Homepage: http://jcp.aip.org/

Journal Information: http://jcp.aip.org/about/about_the_journal

Top downloads: http://jcp.aip.org/features/most_downloaded

Information for Authors: http://jcp.aip.org/authors

\section{ADVERTISEMENT}

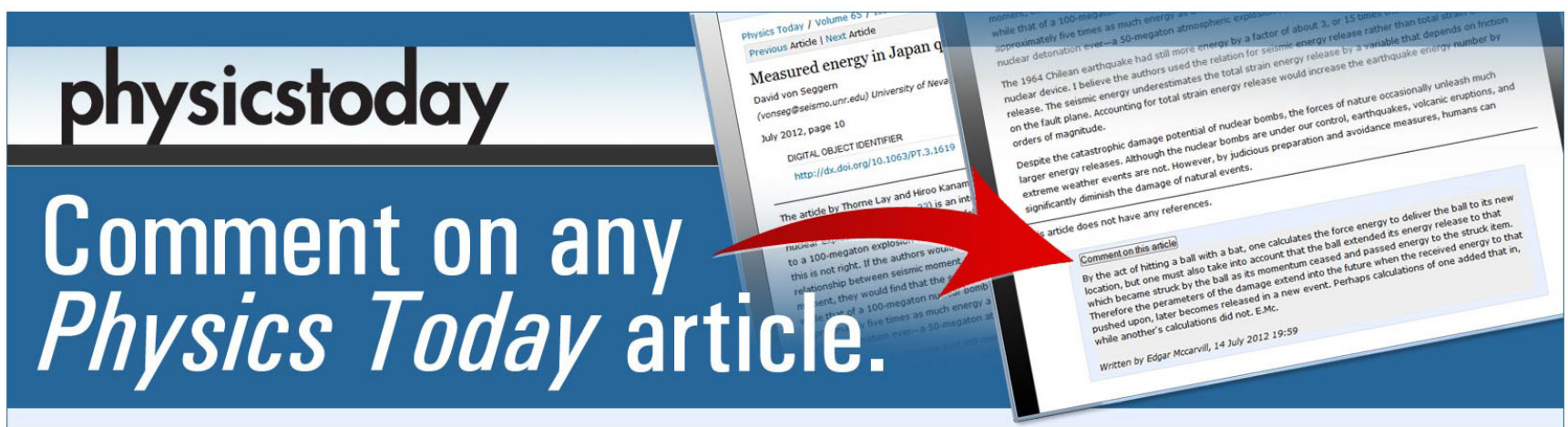




\title{
Surface adsorption in strontium chloride ammines
}

\author{
Andreas L. Ammitzbøll, ${ }^{1}$ Steen Lysgaard, ${ }^{2}$ Agata Klukowska, ${ }^{1}$ Tejs Vegge,${ }^{2}$ \\ and Ulrich J. Quaade ${ }^{1, a)}$ \\ ${ }^{1}$ Amminex Emissions Technology A/S, Gladsaxevej 363, DK-2860 Søborg, Denmark \\ ${ }^{2}$ Department of Energy Conversion and Storage and Center for Atomic-scale Materials Design, \\ Technical University of Denmark, Frederiksborgvej 399, DK-4000, Denmark
}

(Received 14 January 2013; accepted 20 March 2013; published online 22 April 2013)

\begin{abstract}
An adsorbed state and its implications on the ab- and desorption kinetics of ammonia in strontium chloride ammine is identified using a combination of ammonia absorption measurements, thermogravimetric analysis, and density functional theory calculations. During thermogravimetric analysis, ammonia desorption originating from the adsorbed state is directly observed below the bulk desorption temperature, as confirmed by density functional theory calculations. The desorption enthalpy of the adsorbed state of strontium chloride octa-ammine is determined with both techniques to be around $37-39 \mathrm{~kJ} / \mathrm{mol}$. A simple kinetic model is proposed that accounts for the absorption of ammonia through the adsorbed state. @ 2013 AIP Publishing LLC. [http://dx.doi.org/10.1063/1.4800754]
\end{abstract}

\section{INTRODUCTION}

Metal halides are useful materials for absorption of ammonia, forming ammine complexes in the solid state. Applications of the materials include thermochemical heat pumps, ${ }^{1}$ ammonia separation, ${ }^{2}$ and ammonia storage and delivery $y^{3,4}$ for fuel cells ${ }^{5}$ or selective catalytic reduction of $\mathrm{NO}_{\mathrm{x}}$ gasses. ${ }^{6}$ Salts that form complexes with ammonia are very common and show a wide spectrum in binding energies and ammonia capacities. ${ }^{1}$ For reasons of ammonia storage capacity and availability, alkaline Earth halides are very attractive, and for practical reasons of operating temperature and pressure, $\mathrm{CaCl}_{2}$ and $\mathrm{SrCl}_{2}$ are often preferred. Since $\mathrm{SrCl}_{2}$ binds 7 out of 8 ammonia molecules with low binding energy (1-7: $41.4 \mathrm{~kJ} / \mathrm{mol}, 8: 48.1 \mathrm{~kJ} / \mathrm{mol}$ ) compared to 6 out of 8 for $\mathrm{CaCl}_{2}$ (1-4: $41.0 \mathrm{~kJ} / \mathrm{mol}, 5-6: 42.3 \mathrm{~kJ} / \mathrm{mol}, 7: 63.2 \mathrm{~kJ} / \mathrm{mol}$, 8: $69.1 \mathrm{~kJ} / \mathrm{mol}), \mathrm{SrCl}_{2}$ is often the chosen material for practical applications. ${ }^{7}$ The stable ammines of $\mathrm{SrCl}_{2}$ are the monoammine $\operatorname{Sr}\left(\mathrm{NH}_{3}\right) \mathrm{Cl}_{2}$, the di-ammine $\operatorname{Sr}\left(\mathrm{NH}_{3}\right)_{2} \mathrm{Cl}_{2}$, and the octa-ammine $\operatorname{Sr}\left(\mathrm{NH}_{3}\right)_{8} \mathrm{Cl}_{2}$. Depending on temperature and pressure, transitions can go between mono-, di-, and octaammine or directly between mono- and octa-ammine. ${ }^{8}$

For all the above mentioned applications, the absorption/desorption dynamics of ammonia is essential for the performance. In the literature, effective kinetic models of the form

$$
r_{a}=k_{0} \exp \left(-E_{a} / R T\right)(1-s)^{M} f(s, T, p)
$$

have previously been investigated. ${ }^{9-12}$ Here, $E_{a}$ is the activation energy, $R$ is the gas constant, $k_{0}$ and $M$ are constants, $T$ is the absolute temperature, and $s$ is the ammonia saturation degree. Different forms of $f$ have been proposed including a linear term $f=p_{r e l}(s, T)$, a power term $f=p_{\text {rel }}(s, T)^{N}$, and a $\operatorname{logarithmic} \operatorname{term} f=\log p / p_{\text {eq }}$, where $p$ is the pressure and $N$

\footnotetext{
a) Author to whom correspondence should be addressed. Electronic mail: ujq@amminex.com
}

is another constant. The relative pressure $p_{\text {rel }}$ is given by

$$
p_{r e l}(s, T)=\frac{p-p_{e q}(s, T)}{p_{e q}(s, T)},
$$

and the equilibrium pressure $p_{e q}$ is calculated from the van 't Hoff relationship

$$
\log K=\log \frac{p_{e q}}{p_{0}}=-\frac{\Delta H}{R T}+\frac{\Delta S}{R},
$$

where $\Delta H$ and $\Delta S$ are enthalpy and entropy changes associated with desorption, and $K$ is the equilibrium constant. The pressure, $p_{0}$, is the reference pressure - here $p_{0}=1 \mathrm{~Pa}$.

In the present study, absorption rates are measured as a function of pressure at different temperatures, and a deviation from the effective kinetic model (1) is observed at pressures approaching the equilibrium pressure. It is proposed that this indicates the existence of an adsorbed state that is filled at pressures significantly higher than the equilibrium pressure, but less occupied closer to the equilibrium pressure.

Desorption from the adsorbed state is directly demonstrated using thermogravimetric analysis (TGA) and confirmed by density functional theory (DFT). Finally, a simple microkinetic model based on the adsorbed state is analyzed and shown to fit the absorption rate data well.

\section{MEASUREMENT OF ABSORPTION RATE}

The overall principle used to measure absorption rates is: (i) to prepare a reactor of known volume with an amount of strontium chloride, (ii) almost instantly fill the reactor to a high pressure with ammonia, and (iii) follow the pressure as ammonia is absorbed in the salt until the pressure stabilizes close to the equilibrium pressure. The rate, at which the pressure drops, is proportional to the absorption rate. This measurement principle is dynamic rather than a steady state. The main advantage is that the amount of ammonia in the gas phase is small compared to the amount of strontium chloride. This implies that the temperature can be considered constant 


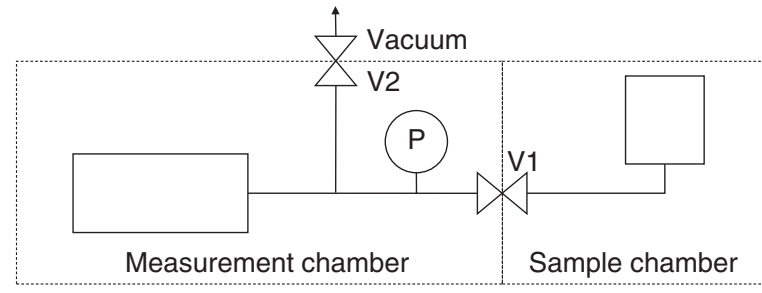

FIG. 1. Sketch of the experimental setup. The chamber volumes are specified in the text.

during absorption, because the heat evolved during absorption of the limited amount of ammonia gas is small. Also, the saturation degree can be considered constant. In this way, the measurement principle has the unique feature that absorption rates as function of ammonia pressure can be measured at different and independently chosen saturation degrees and temperatures.

The experimental setup is shown in Figure 1 (for a detailed description, see Ref. 8). The experiment consists of a sample chamber containing $\mathrm{SrCl}_{2}$ (China Newcent, purity $99.7 \%$, anhydrous, further dried at $200{ }^{\circ} \mathrm{C}$ for $24 \mathrm{~h}$ to less than $0.05 \%$ water content) and a measurement chamber that can be evacuated or filled with ammonia to a certain pressure through the valve V2. The measurement volume is kept at a fixed temperature in a climate chamber. For each cycle of the experiment, the two volumes are first separated by closing the valve V1 between them. This is followed by evacuating the measurement volume and pressurizing it with ammonia to a specified initial pressure. Hereafter, the valve V1 to the sample volume is opened. The pressure equilibrates between the sample chamber and the measurement chamber within milliseconds. From then on, the sample and measurement chambers behave as a batch reactor, and the ammonia pressure, $p(t)$, measured with the pressure sensor $\mathrm{P}$, decreases as ammonia is absorbed in the strontium chloride. After a while, the pressure becomes almost constant in time, which indicates an approach to equilibrium. By repeating the procedure, the salt can be prepared at any saturation degree. During the experiment, the absorption rate is determined from $d p / d t$ and the equation of state

$$
r_{a}=\frac{d n}{d t}=\frac{V}{R T} \frac{d p}{d t} .
$$

From the initial pressure and final pressure in each cycle, the increase in absorbed ammonia per cycle can be calculated. In the measured range, the saturation degree changes less than a few percent during each cycle. Also, the sample is highly dispersed between a high number of steel balls ${ }^{8}$ both to maximize the heat capacity, thus reducing the temperature changes during absorption to less than a few Kelvin, and to minimize any mass transport limitations. If the steel balls were not introduced, the temperature of the $\mathrm{SrCl}_{2}$ would approach the equilibrium temperature instead of being an independently controllable parameter. The saturation degree is verified by measuring the mass of the sample chamber.

A new sample of $\mathrm{SrCl}_{2}$ will break up and form a porous structure upon ammonia absorption and desorption. ${ }^{13}$ Before the experiment is started, the sample is saturated with am-

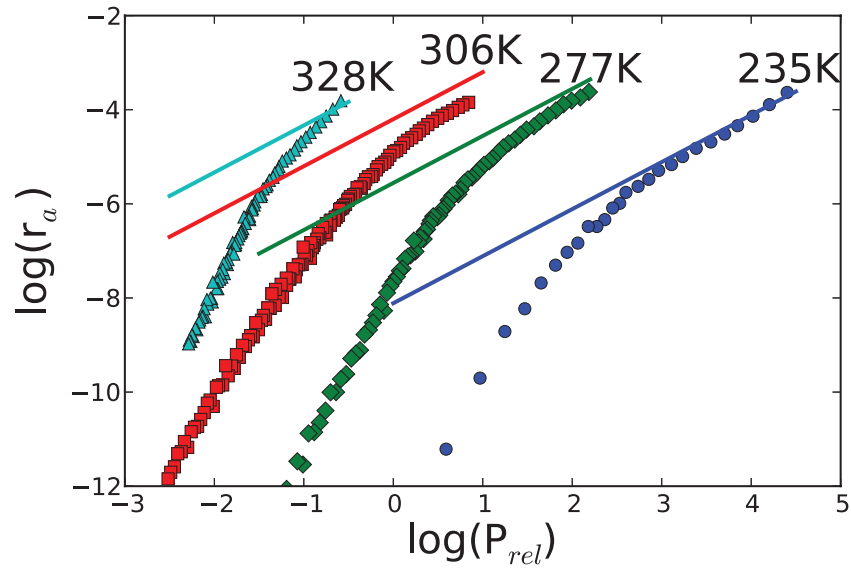

FIG. 2. Relationship between logarithms of the absorption rate in $\operatorname{mol}\left(\mathrm{NH}_{3}\right) / \mathrm{mol}\left(\mathrm{SrCl}_{2}\right) / \mathrm{s}$ and the relative pressure. The saturation degree in the displayed measurements is $s=0.3$.

monia and degassed several times to prepare a stable sample with a non-changing structure. The experiment contains $5.1 \mathrm{~g} \mathrm{SrCl}_{2}$ and the gas volume in the two volumes $\mathrm{V} 1$ and V2 together is $90 \mathrm{ml}$.

All together, absorption rates as function of ammonia pressure can be obtained for specific saturation degrees and temperatures.

In Figure 2, measured absorption rates $r_{a}$ are plotted as function of the relative pressure (2) for four temperatures.

The best fit of the proposed model (1) to the data in Figure 2 is obtained with the linear expression for $f$

$$
r_{a}=k_{0} \exp \left(-E_{a} / R T\right)(1-s) p_{r e l}(s, T),
$$

with $k_{0}=9.5 \times 10^{3} \mathrm{~mol} / \mathrm{s}, E_{a}=32.9 \mathrm{~kJ} / \mathrm{mol}$, and $s=0.3$. The relative pressure, $p_{r e l}$, is calculated from (2) using literature values of $\Delta H=41.4 \mathrm{~kJ} / \mathrm{mol}$ and $\Delta S=228.8 \mathrm{~J} /(\mathrm{mol} \mathrm{K}){ }^{1}$

The model fits well at high relative pressures, but deviates at low relative pressures.

It is proposed, that this indicates the existence of an adsorbed state in the absorption dynamics: The linear regime at high pressures, where the absorption rate is high, is interpreted to belong to a high ammonia surface coverage. At lower pressures, the surface coverage will shift to lower values and the rate will drop.

\section{THERMOGRAVIMETRIC ANALYSIS OF THE ADSORBED STATE}

Thermogravimetric analysis is a technique where a sample can be heated while monitoring the mass change with a balance. In a standard configuration, the sample is heated in a (typically) non-corrosive gas stream at ambient pressure. For measurements with corrosive gasses at varying pressures, the sample and gas stream need to be isolated from the balance and electronics. The present investigations are performed on a high pressure TGA (HP-TGA, Isosorp Gas, LP-flow) from Rubotherm, where the sample and sample holder are magnetically coupled to the balance and electronics. The HP-TGA 


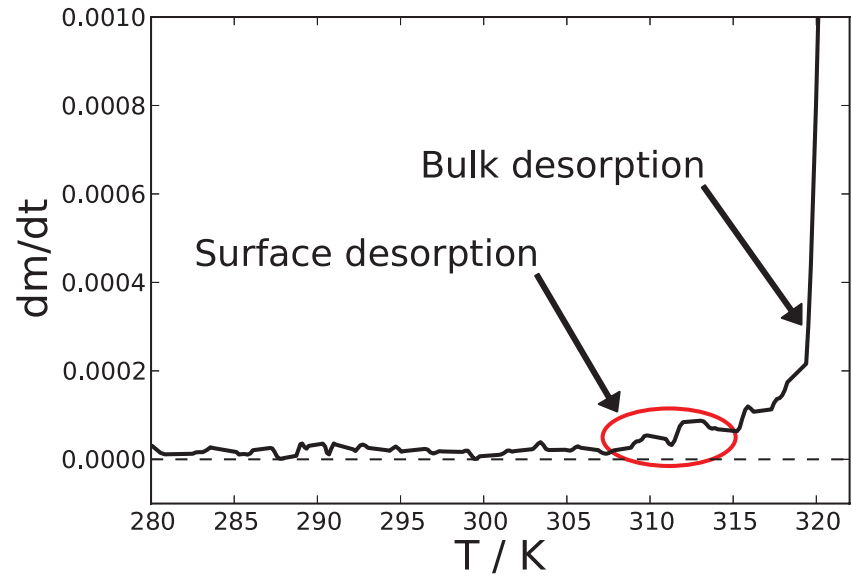

FIG. 3. TGA measurement showing release of ammonia prior to the onset of bulk desorption. This is interpreted as desorption from the surface.

works in an ammonia pressure of 0-5 bars and a temperature range of $0{ }^{\circ} \mathrm{C}-400{ }^{\circ} \mathrm{C}$ with a mass resolution of $10 \mu \mathrm{g}$.

A $\mathrm{SrCl}_{2}$ sample of $226 \mathrm{mg}$ is first saturated and degassed several times in the HP-TGA to create a stable structure of the sample with high porosity and surface area. The measurement cycle hereafter is (i) to fully saturate the sample for 120-180 min at $0{ }^{\circ} \mathrm{C}$ and an ammonia pressure of 3 bars. (ii) Stabilize the start temperature, $T_{s}$, and pressure, $p$, for the HP-TGA measurement. (iii) Ramp the temperature at $1 \mathrm{~K} / \mathrm{min}$ to the desired final temperature $T_{f}$.

A representative desorption measurement in 2 bars of ammonia is shown in Figure 3. The temperature is ramped from $T_{s}=273 \mathrm{~K}$ to $T_{f}=323 \mathrm{~K}$ at $1 \mathrm{~K} / \mathrm{min}$. The plotted data are $\mathrm{dm} / \mathrm{dt}$, the mass change per time unit. The fast desorption above $320 \mathrm{~K}$ is desorption from bulk. Below $320 \mathrm{~K}$, the mass changes are close to the noise limit, but it is clear that the onset of desorption is observed around $309 \mathrm{~K}$. This is interpreted as desorption from the surface.

The experiment is repeated at four different pressures as seen in Table I.

The pressures and desorption temperatures $T_{\text {desorption }}$ of Table I are plotted in Figure 4 and the fitted enthalpy change and entropy change associated with desorption from the adsorbed state are $\Delta H_{\text {surf }}=39.2 \mathrm{~kJ} / \mathrm{mol}$ and $\Delta S_{\text {surf }}$ $=228 \mathrm{~J} /(\mathrm{mol} \mathrm{K})$.

Desorption from bulk is well understood and expected, when the temperature exceeds the bulk equilibrium temperature at a given pressure. The general relation between pres-

TABLE I. List of TGA experiments: For each experiment the pressure, the temperature interval, and the temperature, $T_{\text {desorption }}$, at which desorption from the surface begins, are listed. The asterisk denotes the dataset plotted in Figure 3.

\begin{tabular}{lccc}
\hline \hline Pressure (bar) & $T_{i}(\mathrm{~K})$ & $T_{f}(\mathrm{~K})$ & $T_{\text {desorption }}(\mathrm{K})$ \\
\hline 0.5 & 273 & 303 & 285 \\
1 & 293 & 373 & 296 \\
1 & 273 & 308 & 296 \\
$2^{*}$ & 273 & 323 & 309 \\
2 & 273 & 323 & 311 \\
2.5 & 273 & 323 & 315 \\
\hline \hline
\end{tabular}

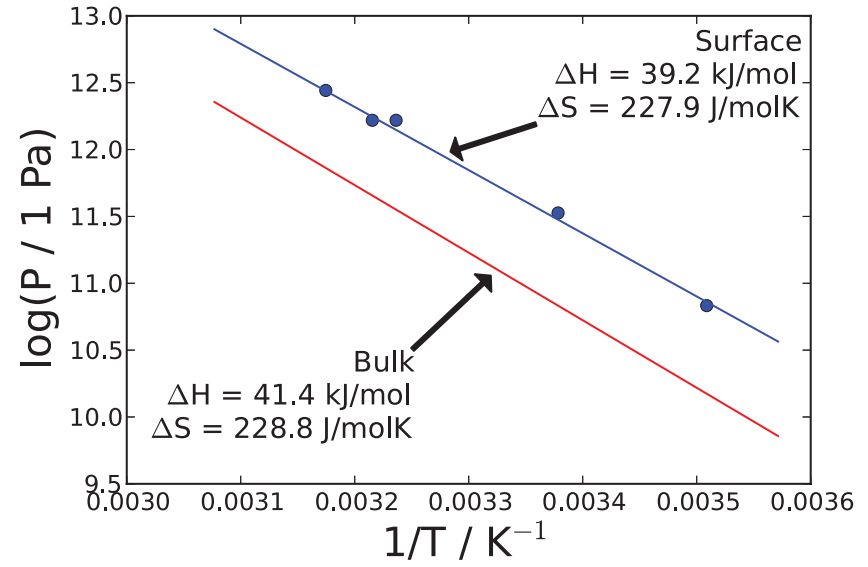

FIG. 4. Van 't Hoff plot for the adsorbed state on the surface and bulk state. The data points for the adsorbed state are the pressures $p$ and temperatures $T_{\text {desorption }}$ of Table I. The fit to data yields $\Delta H_{\text {surf }}=39.2 \mathrm{~kJ} / \mathrm{mol}$ and $\Delta S_{\text {surf }}$ $=228 \mathrm{~J} /(\mathrm{mol} \mathrm{K})$. For the bulk state, the plotted line is based on the literature value of $\Delta H_{8-1}=41.4 \mathrm{~kJ} / \mathrm{mol}$ and $\Delta S_{8-1}=228.8 \mathrm{~J} /(\mathrm{mol} \mathrm{K}){ }^{1}$

sure and temperature at equilibrium is given by (3). For desorption from fully saturated $\operatorname{Sr}\left(\mathrm{NH}_{3}\right)_{8} \mathrm{Cl}_{2}$, the enthalpy and entropy changes are $\Delta H_{8-1}=41.4 \mathrm{~kJ} / \mathrm{mol}$ and $\Delta S_{8-1}$ $=228.8 \mathrm{~J} /(\mathrm{mol} \mathrm{K}),{ }^{1}$ where the subscript denotes going from the octa-ammine phase to the mono-ammine phase. From this, the equilibrium temperature related to desorption from bulk can be calculated as plotted in Figure 4.

It is clearly seen from Figure 4 that desorption starts at a significantly lower temperature than expected from the equilibrium temperature of ammonia absorbed in bulk $\mathrm{Sr}\left(\mathrm{NH}_{3}\right)_{8} \mathrm{Cl}_{2}$. This is consistent with desorption from an adsorbed state with lower binding energy than the bulk states.

To estimate the possible amount of ammonia on the surface, the surface area of saturated $\mathrm{SrCl}_{2}$ is assumed to be of the order of $50 \mathrm{~m}^{2} / \mathrm{g}$, which has been reported for similar metal ammine chlorides. ${ }^{14}$ Setting the area of a surface bound ammonia molecule to $2.5 \times 10^{-19} \mathrm{~m}^{2}$ (a reasonable assumption as shown by DFT calculations in Figure 5), it is possible to adsorb $2 \mathrm{mg}$ of ammonia on the surface, which is roughly the mass change observed from the onset of desorption at $309 \mathrm{~K}$ until bulk desorption kicks in at around $320 \mathrm{~K}$ as seen in Figure 3. ( $0.226 \mathrm{~g}$ of strontium chloride can absorb a total of $0.19 \mathrm{~g}$ of ammonia meaning that the ratio between surface sites and bulk sites is about 1:100 in the experiment.)

\section{DFT CALCULATIONS}

Density functional theory ${ }^{15,16}$ calculations were performed using the ASE framework ${ }^{17}$ with the GPAW ver. 0.7.6383 DFT code ${ }^{18}$ GPAW is a grid-based real space implementation of the Projector Augmented Wave (PAW) method. ${ }^{19}$ A van der Waals corrected exchange correlation functional $(\mathrm{vdW}-\mathrm{DF})^{20}$ that includes long range correlation effects, important for systems, where hydrogen bonds are present, is used. The Brillouin zone was k-point sampled using a Monkhorst-Pack scheme. ${ }^{21}$ For each structure, the kpoint sampling, grid spacing, and added vacuum were tested for convergence of the energy. A grid spacing of $0.18 \AA$, a $\mathrm{k}$-point sampling of $(4,2,1)(1$ in the direction normal to the 

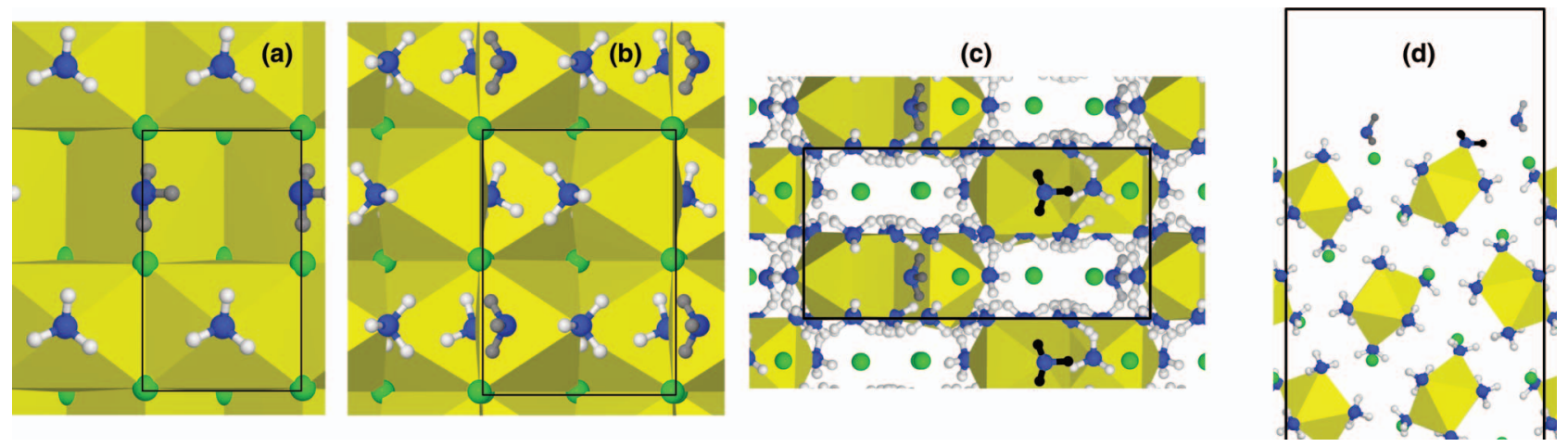

FIG. 5. View of the surface atomic structures as calculated with DFT. Green: $\mathrm{Cl}$, blue: N, white: $\mathrm{H}$ and $\mathrm{Sr}$ is in the center of the yellow coordination polyhedra. The adsorbed $\mathrm{NH}_{3}$ are indicated by having grey hydrogen. The black line indicates the calculational unit cell. (a) The mono-ammine (010) surface with full coverage. The unit cell indicated is $4.69 \times 7.72 \AA^{2}$. (b) The di-ammine (001) surface with half coverage. The unit cell is $6.23 \times 8.45 \AA^{2}$. (c) Top view of the octa-ammine (100) surface with full coverage. Dark and light grey hydrogen indicates $\theta=0.5$ and $\theta=1.0$, respectively. The $\mathrm{NH}_{3}$ molecule with black hydrogen is weakly bound as explained in the text. The unit cell indicated is $7.51 \times 15.4 \AA^{2}$. (d) Side view of the octa-ammine surface structure. Half of the calculational vacuum between layers is indicated with the unit cell.

surface) and $15 \AA$ of vacuum between slabs were sufficient for all structures. The surfaces were made of four layers of the material with the bottom two layers fixed. All reported DFT enthalpies are after relaxation of the atomic positions with a quasi-Newton type optimization algorithm. ${ }^{22}$

\section{A. Modeling the surfaces}

Surfaces were made from bulk crystals of the different ammines (see Ref. 8 for more information about the bulk structures). Cuts were made along different low Miller index planes to simulate possible surface terminations and the energy cost of exposing a surface from the bulk was found. The relaxation usually led to a small contraction in the direction perpendicular to the surface. The facets with the lowest surface energy were used for studying adsorption energies of $\mathrm{NH}_{3}$, as these surfaces are expected to dominate the real surface of the material. The surface indexes are indicated in Table II. For all surfaces, the general rule of thumb was that the surface termination should break the least bonds, thereby letting the surface atoms have the highest possible coordination number. Adsorbate $\mathrm{NH}_{3}$ molecules were investigated in different positions that maximized the number of hydrogen bonds formed between the adsorbates and the surface.

\section{B. DFT results}

For $\mathrm{Sr}\left(\mathrm{NH}_{3}\right) \mathrm{Cl}_{2}$, only one surface site is stable in the unit cell, the energy corresponding to half coverage $(\theta=0.5)$ is therefore calculated by doubling one side of the

TABLE II. Energies of the adsorbed $\mathrm{NH}_{3}$ molecules in half of the stable sites $(\theta=0.5)$ and all of the stable sites $(\theta=1.0)$.

\begin{tabular}{lcr}
\hline \hline & \multicolumn{2}{c}{ Adsorbed state energy $(\mathrm{kJ} / \mathrm{mol})$} \\
\cline { 2 - 3 } Material & $\theta=0.5$ & $\theta=1.0$ \\
\hline $\mathrm{Sr}\left(\mathrm{NH}_{3}\right)_{2} \mathrm{Cl}_{2}(010)$ & 27.5 & 29.2 \\
$\mathrm{Sr}\left(\mathrm{NH}_{3}\right)_{2} \mathrm{Cl}_{2}(001)$ & 35.9 & 34.7 \\
$\mathrm{Sr}\left(\mathrm{NH}_{3}\right)_{8} \mathrm{Cl}_{2}(100)$ & 37.0 & 29.0 \\
\hline \hline
\end{tabular}

unit cell in the surface and filling only one of the equivalent sites. For the other phases, two stable surface sites exist. The energy for full coverage $(\theta=1.0)$ is defined as: $\left(E_{\theta=1}\right.$ $\left.-\left(E_{\theta=0.0}+2 E_{\mathrm{NH} 3}\right)\right) / 2$, i.e., the average of the adsorbed ammonia molecules.

The adsorbed $\mathrm{NH}_{3}$ molecules form long hydrogen bonds to the $\mathrm{Cl}$ atoms in the surface. For the mono-ammine, the surface site is asymmetric and has one short H-bond on $2.72 \AA$ at $161^{\circ}$, and one longer on $2.87 \AA$ at $142^{\circ}$. For the di-ammine, the hydrogen bonds to $\mathrm{Cl}$ atoms are of equal length and angle, $2.85 \AA$ and $142^{\circ}$, respectively. Furthermore, a hydrogen bond to the $\mathrm{N}$ on the adsorbed ammonia of only $2.32 \AA$ and $156^{\circ}$ is established; this is what stabilizes the di-ammine surface site more than the mono-ammine (see Figure 5(b)).

The second adsorption energy, $\theta=1$, for the monoammine is slightly higher than the first, probably owing to interaction with the first adsorbed $\mathrm{NH}_{3}$. For the di-ammine, the second adsorbs in almost equivalent environments as the first just rotated $180^{\circ}$, leading to almost equal adsorption energies. The surface sites on the octa-ammine are different in hydrogen bond length and angles giving energies with large differences. The strongly adsorbed $\mathrm{NH}_{3}$ (indicated with dark grey hydrogen in Figures 5(c) and 5(d)) molecule forms two hydrogen bonds of $3.07 \AA$ and $3.16 \AA$ at $160^{\circ}$ and $159^{\circ}$, respectively. The weakly adsorbed $\mathrm{NH}_{3}$ (marked with light grey hydrogen in Figures 5(c) and 5(d)) has distances that can hardly be called hydrogen bonds of $3.67 \AA$ at $161^{\circ}$ and $3.54 \AA$ at $163^{\circ}$. Since the hydrogen bonds are more than $3 \AA$, it is more reasonable to ascribe the stability of the adsorbed state to van der Waals interactions. It should be noted that the octa-ammine when forming a surface exposes one $\mathrm{NH}_{3}$ molecule (marked with black hydrogen in Figures 5(c) and 5(d)) bound by only $37.8 \mathrm{~kJ} / \mathrm{mol}$ almost the same as the first adsorbed $\mathrm{NH}_{3}$. The other phases do not expose weakly bound $\mathrm{NH}_{3}$ when the surface is formed.

\section{MICROKINETIC MODEL}

With the knowledge of the adsorbed state it is possible to develop a simple microkinetic model of absorption. The 


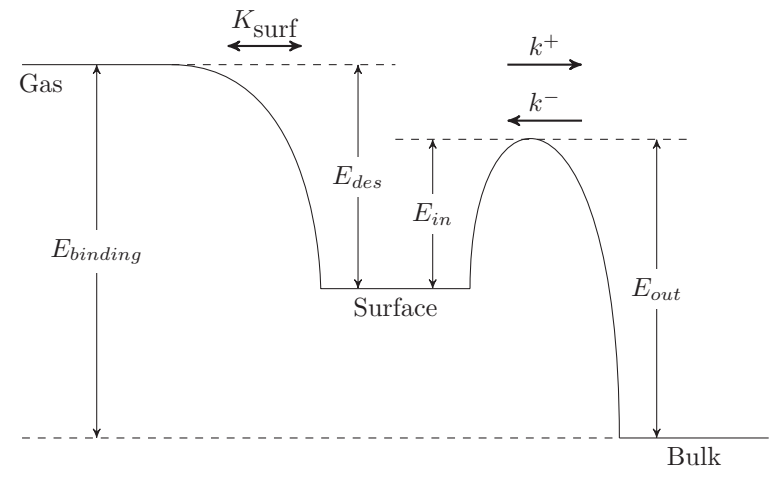

FIG. 6. Model describing absorption of ammonia through a stable adsorbed state.

simplest possible model is adsorption on the surface followed by crossing a barrier to the bulk as shown in Figure 6,

$$
\begin{array}{r}
\mathrm{NH}_{3}+* \leftrightarrow \mathrm{NH}_{3}^{*} \quad \text { adsorption, } \\
\mathrm{NH}_{3}^{*}+\not \leftrightarrow \leftrightarrow \mathrm{NH}_{3}^{\alpha}+* \quad \text { diffusion to bulk, }
\end{array}
$$

where "*” denotes a surface site and "o" a bulk site.

The simple model does not include any transport limitations by, e.g., bulk diffusion inside the crystals. From collision theory, it can easily be verified that for all realistic values, the time-scale to reach equilibrium between the gas phase and the surface is several orders of magnitude faster than all other time-scales in the system. ${ }^{23}$ As a consequence, the adsorption reaction (5a) can be considered in equilibrium, as in Langmuir adsorption, in which case the surface coverage can be written ${ }^{23}$

$$
\theta=\frac{K_{\text {surf }} p_{\mathrm{NH}_{3}}}{1+K_{\text {surf }} p_{\mathrm{NH}_{3}}}
$$

where $\theta$ is the surface coverage and the equilibrium constant $K_{\text {surf }}$ is given from (3) with $\Delta H_{\text {surf }}=39.2 \mathrm{~kJ} / \mathrm{mol}$ and $\Delta S_{\text {surf }}$ $=228 \mathrm{~J} /(\mathrm{mol} \mathrm{K})$ (Figure 4).

The rate equation for crossing the barrier between surface and bulk is

$$
\begin{gathered}
\gamma \varphi^{\prime}(t)=k^{+} \theta(1-\varphi)-k^{-} \varphi(1-\theta), \\
k^{+}=v_{\text {in }} \exp -\frac{\Delta E_{\text {in }}}{k_{b} T}, \\
k^{-}=v_{\text {out }} \exp -\frac{\Delta E_{\text {out }}}{k_{b} T},
\end{gathered}
$$

where $\varphi$ is the occupancy of bulk sites and $\gamma$ is the ratio between the number of bulk sites and surface sites.

To model the batch absorption experiments depicted in Figure 2, the mass balance between gas molecules and molecules on the surface and in the bulk is needed,

$$
p^{\prime}(t)=-\frac{N_{s} k_{b} T}{V}\left(\gamma \varphi^{\prime}(t)+\theta^{\prime}(t)\right) .
$$

Here, $N_{s}$ is the number of surface sites and $V$ is the gas volume in the reactor.

The model can be integrated using the physical parameters of the reactor and the binding energy of the adsorbed state
TABLE III. Parameters used for the microkinetic model.

\begin{tabular}{lc}
\hline \hline$v_{\text {in }}$ & $30 \mathrm{~Hz}$ \\
$v_{\text {out }}$ & $30 \mathrm{~Hz}$ \\
$\Delta E_{\text {in }}$ & $10 \mathrm{~kJ} / \mathrm{mol}$ \\
$\Delta E_{\text {out }}$ & $\Delta E_{\text {tot }}-\Delta E_{\text {surf }}+\Delta E_{\text {in }}$ \\
$\Delta E_{\text {tot }}$ & $41.4 \mathrm{~kJ} / \mathrm{mol}$ \\
$\Delta E_{\text {surf }}=\Delta H_{\text {surf }}$ & $39.2 \mathrm{~kJ} / \mathrm{mol}^{-5} \mathrm{~m}^{3}$ \\
$V$ & $9 \times 10^{-5}$ \\
$\gamma$ & 100 \\
\hline
\end{tabular}

found from the TGA experiments. A complete list of values is found in Table III.

In Figure 7, the microkinetic model is plotted together with the experimental data of Figure 2. It is seen that absorption through an adsorbed state is consistent with the data. The only parameters for which there is no independent prediction are the effective attempt frequencies $v_{i n}$, $v_{\text {out }}$, and the barrier $\Delta E_{\text {in }}$. Values for these parameters are chosen to make the best fit to data. A value of $30 \mathrm{~Hz}$ for the frequencies is too low to be a vibration frequency. Instead, it is understood as an effective value taking into account that the atomic configuration in the crystal change significantly when an ammonia molecule moves from one site to another. The barrier $\Delta E_{i n}=10 \mathrm{~kJ} / \mathrm{mol}$ is the barrier an ammonia molecule has to surpass when going from the surface into the bulk.

It is a quite small barrier, but reflects the fact that the absolute absorption rates do not change much with temperature in the investigated temperature range as seen in Figure 7. The absorption rate, thus, mainly depends on the surface coverage. The model is not fitted to reach the exact equilibrium pressures. As a consequence, the relative pressure $p_{\text {rel }}$ is not well defined, and the x-axis of Figure 7 linear in pressure in contrast to Figure 2.

\section{DISCUSSION}

In the TGA experiments, the sample is fully saturated and comparison to DFT calculations should be done for the

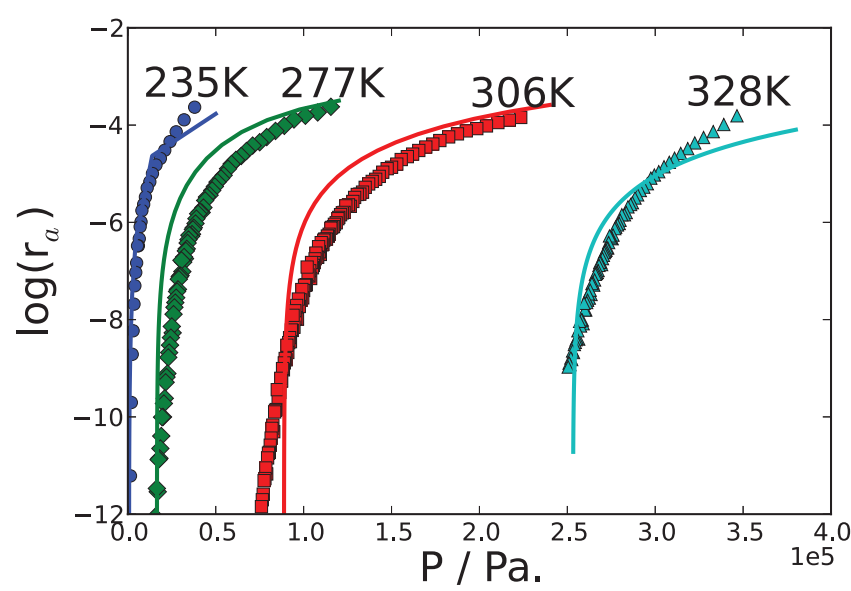

FIG. 7. The desorption measurements at $235 \mathrm{~K}$ with blue circles, $277 \mathrm{~K}$ green diamonds, $306 \mathrm{~K}$ with red squares and $328 \mathrm{~K}$ with cyan triangles. The full lines represent the simple microkinetic model at the corresponding temperature. 
octa-ammine phase only. The measured energy of the adsorbed state of $39.2 \mathrm{~kJ} / \mathrm{mol}$ is very close to the predicted 37.0 $\mathrm{kJ} / \mathrm{mol}$ for octa-ammine (Table II) for the expected $\theta=0.5$ coverage at the experimental conditions.

In the absorption rate experiments, the saturation degrees correspond to mostly mono-ammine or di-ammine and some octa-ammine. For the saturation degree of $30 \%$, the sample will be $20 \%$ octa-ammine, if only a stable mono-ammine phase is assumed to exist, or $6 \%$ octa-ammine assuming a stable di-ammine phase to exist. ${ }^{8}$ The experimental data should therefore be dominated by either the mono-ammine phase or the di-ammine phase, and the comparison between absorption rate experiments and DFT calculations should therefore be done using the DFT calculations for mono- and di-ammine.

However, fitting the model to the data in Figure 7 with the predicted energy of the adsorbed state of the mono- and di-ammine, give poor fits - especially for the lowest temperature. Only the high surface energy of the octa-ammine give good fits for all temperatures. This can be explained by the dynamics of absorption: The ammonia molecules adsorb on the surface, cross the barrier to the bulk sites closest to the surface, and then diffuse deeper into the material. This will induce a concentration gradient, where the bulk sites close to the surface can be dominated by octa-ammine.

Different mechanisms of ammonia diffusion in $\mathrm{MgCl}_{2}$ ammines have been investigated recently. ${ }^{14,24}$ The diffusion between layers in Ref. 24 can be considered equivalent to the diffusion of adsorbed $\mathrm{NH}_{3}$ molecules into the bulk of the mono- and di-ammine, as the layers are constructed almost identically in $\mathrm{MgCl}_{2}$ and $\mathrm{SrCl}_{2}$. The barriers for diffusion between layers in the mono- and di-ammines were found to be more than $1 \mathrm{eV}(\sim 96.5 \mathrm{~kJ} / \mathrm{mol})$ that is a much larger value than observed here thereby ruling out diffusion as the mechanism giving rise to the different absorption rates at high and low pressures.

Barriers in the $\mathrm{MgCl}_{2}$ hexamine are approximately 0.5 $\mathrm{eV}(\sim 48 \mathrm{~kJ} / \mathrm{mol})$, much higher than the estimate of $\Delta E_{\text {in }}$ in our microkinetic model, however, the octa-ammine is a more open structure as evident in Figures 5(c) and 5(d), and more space leads to smaller barriers. If the weakly bound $\mathrm{NH}_{3}$ (marked with black in Figures 5(c) and 5(d)) is responsible for the adsorbed state, it is easy to imagine a very small barrier for diffusion from the adsorbed state into the bulk as this would just necessitate a move of the $\mathrm{NH}_{3}$ molecule to an adjacent position in the same $\mathrm{Sr}-\mathrm{NH}_{3}$ complex, and no $\mathrm{Sr}-\mathrm{N}$ bond would be broken and the barrier $\Delta E_{\text {in }}$ would thus be very small.

Assuming that only a stable octa-ammine phase dominates in the experiments, the DFT surface site energy to com- pare with the experimental desorption enthalpy would be 37.0 $\mathrm{kJ} / \mathrm{mol}$ (half coverage). That is in good agreement with the experimental finding of $39.2 \mathrm{~kJ} / \mathrm{mol}$, leading us to conclude that stable $\mathrm{NH}_{3}$ adsorbed states exist and play an important role in the ammonia absorption in metal halide ammines.

\section{ACKNOWLEDGMENTS}

The authors would like to acknowledge the European Graduate School on Sustainable Energy - The Molecular Approach, the Danish Center for Scientific Computing, the Catalysis for Sustainable Energy (CASE) Initiative, the Center of Atomic-Scale Materials Design (CAMD), and the Danish National Advanced Technology Foundation (DNATF). CASE is funded by the Danish Ministry of Science, Technology and Innovation.

${ }^{1}$ E. Lepinasse and B. Spinner, Int. J. Refrigeration 17, 309 (1994).

${ }^{2}$ C. Y. Liu and K. Aika, Bull. Chem. Soc. Jpn. 77, 123 (2004).

${ }^{3}$ C. H. Christensen, R. Z. Sørensen, T. Johannessen, U. J. Quaade, K. Honkala, T. D. Elmøe, R. Køhler, and J. K. Nørskov, J. Mater. Chem. 15, 4106 (2005).

${ }^{4}$ A. Klerke, C. H. Christensen, J. K. Nørskov, and T. Vegge, J. Mater. Chem. 18, 2304 (2008).

${ }^{5}$ D. Chakraborty, H. N. Petersen, C. Elkjær, A. Cagulada, and T. Johannessen, Fuel Cells Bull. 2009, 12 (2009).

${ }^{6}$ T. Elmøe, R. Sørensen, U. Quaade, C. Christensen, J. K. Nørskov, and T. Johannessen, Chem. Eng. Sci. 61, 2618 (2006).

${ }^{7}$ T. Vegge, R. Z. Sørensen, A. Klerke, J. S. Hummelshøj, T. Johannessen, J. K. Nørskov, and C. H. Christensen, "Indirect hydrogen storage in metal ammines," in Solid State Hydrogen Storage: Materials and Chemistry, edited by G. Walker (Woodhead Publishing, 2008), pp. 533-568.

${ }^{8}$ S. Lysgaard, A. L. Ammitzbøll, R. E. Johnsen, P. Norby, U. Quaade, and T. Vegge, Int. J. Hydrogen Energy 37, 18927 (2012).

${ }^{9}$ M. Lebrun and B. Spinner, Chem. Eng. Sci. 45, 1743 (1990).

${ }^{10}$ P. Neveu and J. Castaing-Lasvignottes, Appl. Therm. Eng. 17, 501 (1997).

${ }^{11}$ V. Goetz and A. Marty, Chem. Eng. Sci. 47, 4445 (1992).

${ }^{12}$ H. Huang, G. Wu, J. Yang, Y. Dai, W. Yuan, and H. Lu, Sep. Purif. Technol. 34, 191 (2004).

${ }^{13}$ H. S. Jacobsen, H. A. Hansen, J. W. Andreasen, Q. Shi, A. Andreasen, R. Feidenhans'1, M. M. Nielsen, and T. Vegge, Chem. Phys. Lett. 441, 255 (2007).

${ }^{14}$ R. Z. Sørensen, J. S. Hummelshøj, A. Klerke, J. B. Reves, T. Vegge, J. K. Nørskov, and C. H. Christensen, J. Am. Chem. Soc. 130, 8660 (2008).

${ }^{15}$ P. Hohenberg and W. Kohn, Phys. Rev. 136, B864 (1964).

${ }^{16}$ W. Kohn and L. J. Sham, Phys. Rev. 140, A1133 (1965).

${ }^{17}$ S. R. Bahn and K. W. Jacobsen, Comput. Sci. Eng. 4, 56 (2002).

${ }^{18}$ J. Mortensen, L. Hansen, and K. Jacobsen, Phys. Rev. B 71, 035109 (2005).

${ }^{19}$ P. E. Blöchl, Phys. Rev. B 50, 17953 (1994).

${ }^{20}$ M. Dion, H. Rydberg, E. Schroder, D. C. Langreth, and B. I. Lundqvist, Phys. Rev. Lett. 92, 246401 (2004).

${ }^{21}$ H. Monkhorst and J. Pack, Phys. Rev. B 13, 5188 (1976).

${ }^{22}$ P. Maragakis, S. A. Andreev, Y. Brumer, D. R. Reichman, and E. Kaxiras, J. Chem. Phys. 117, 4651 (2002).

${ }^{23}$ I. Chorkendorff and J. W. Niemantsverdriet, Concepts of Modern Catalysis and Kinetics (Wiley-VCH Verlag GmbH \& Co. KGaA, Weinheim, 2003).

${ }^{24}$ A. Tekin, J. S. Hummelshøj, H. S. Jacobsen, D. Sveinbjörnsson, D. Blanchard, J. K. Nørskov, and T. Vegge, Energy Environ. Sci. 3, 448 (2010). 